\title{
The Need to Consider Pregnancy As a Biological Variable to Reduce Preventable Suffering Related to Pregnancy
}

\author{
David A. Thomas, PhD, ${ }^{1}$ Hannah E. Bruckheim, ${ }^{2}$ and Jamie M. White, MS ${ }^{1}$
}

\begin{abstract}
Maternal morbidity and mortality constitute a national health crisis, and pain is a significant component of maternal morbidity. One important way to reduce maternal morbidity is to reduce the pain associated with pregnancy. Unfortunately, our understanding of how to reduce pain in women is hampered because, historically, mostly male subjects have been used in the study of pain. However, more recently, females increasingly have been included in pain research studies, and astounding differences in how males and females process pain have been uncovered. Moreover, pain in nonpregnant women differs in many ways from pain experienced by pregnant women. We argue here that to better address maternal morbidity, we must better address the pain associated with pregnancy. Furthermore, just as it is important to include both men and women in pain research to better understand pain in both sexes, conducting pain research in pregnant women is essential to finding ways to reduce pain in pregnant women.
\end{abstract}

Keywords: pain, pregnancy, analgesia, maternal morbidity

\section{Introduction}

H ISTORICALLY, BIOMEDICAL RESEARCH has focused on the study of males, and clinical trial subjects predominantly have been males because of a misconception that males and females were essentially the same, except that female hormones could interfere with the interpretation of the data. This misconception has not only led to erroneous conclusions about the health of women but also has been proven to be a grossly incorrect assumption. ${ }^{1}$

Despite the passage of legislation that mandates the inclusion of women in clinical studies, this issue still pervades the scientific community. For example, from the 120 journal articles published in the New England Journal of Medicine in 2001 , only $24.6 \%$ of the participants enrolled were women. ${ }^{2}$ In addition, pregnant women traditionally have been excluded from clinical trials because they were deemed a vulnerable population and became a protected class of human subjects by the Common Rule, ${ }^{3}$ which—although protective-also means that research that could lead to reducing diseases and suffering in pregnant women often is not conducted.
In 2016, to advance biomedical research that would promote the health of males and females, the National Institutes of Health (NIH) adopted the Sex As a Biological Variable (SABV) policy (https://orwh.od.nih.gov/sex-gender/nihpolicy-sex-biological-variable), which mandated the inclusion of both sexes in research, with some exceptions. The policy states that "NIH expects that SABV will be factored into research designs, analyses, and reporting in vertebrate animal and human studies. Strong justification from the scientific literature, preliminary data, or other relevant considerations must be provided for applications proposing to study only one sex."

The SABV policy applies across the spectrum of biomedical research and is making a significant difference, but it is especially needed in the field of pain research. Chronic pain affects about 100 million Americans and costs our society between $\$ 550$ billion and $\$ 650$ billion annually, ${ }^{4}$ more than any other health condition. Pain is more prevalent in women than in men, ${ }^{5}$ and in almost all studies, females have been found to be more sensitive to pain than males. ${ }^{6}$ Despite the impact of pain, especially in women, we still struggle to manage it effectively because pain is often difficult and

\footnotetext{
${ }^{1}$ Office of Research on Women's Health, Office of the Director, National Institutes of Health, Bethesda, Maryland, USA.

${ }^{2}$ Office of FOA Development and Referral, Division of Extramural Research Activities, National Heart, Lung, and Blood Institute, National Institutes of Health, Bethesda, Maryland, USA.

(C) David A. Thomas et al. 2021; Published by Mary Ann Liebert, Inc. This Open Access article is distributed under the terms of the Creative Commons Attribution Noncommercial License (http://creativecommons.org/licenses/by-nc/4.0/) which permits any noncommercial use, distribution, and reproduction in any medium, provided the original author(s) and the source are cited.

Correction added on February 19, 2021 after first online publication of November 20, 2020: The article reflects Open Access, with copyright transferring to the author(s), and a Creative Commons Attribution Noncommercial License (CC-BY-NC) added (http:// creativecommons.org/licenses/by-nc/4.0/).
} 
expensive to treat, and the overprescribing of opioids as a "quick fix" to alleviate pain has set the foundation for the opioid crisis in the United States. We need to do better for men and women in pain.

Why are we not better able to treat pain? Part of the reason is that we historically have done most of the preclinical pain research on males and unsuccessfully have tried to apply these findings to females. Between 1996 and 2005, 79\% of the preclinical research studies with rodent subjects published in the journal Pain tested male rats or male mice only, ${ }^{7}$ and although more females are being used in pain research since the implementation of the NIH SABV policy, nearly half of the animal studies published in Pain in 2019 were still male-only studies. ${ }^{8}$

Despite a historical bias toward conducting pain research (and biomedical research, in general) predominantly in males, leading to a "male-based literature," 8 more recent research is making it dramatically clear that males and females have very different pain-processing systems that are sensitive to different treatment approaches.

One recent review by Jeffery Mogil, ${ }^{8}$ a leader in this field, highlighted many of these differences. Mogil presents almost 50 articles that report sex differences in genetics related to pain processing. For example, Smith et al. ${ }^{9}$ found a genetic predictor of temporomandibular joint disorder (TMJD) that is predictive of TMJD only in males. Mogil also presents the findings from about 30 articles addressing sex differences in the neural mediation of pain. This includes the work of Anne Murphy and colleagues who have discovered that the descending pain control system-first described in the $1970 \mathrm{~s}^{10,11}$ and extensively studied since-works very differently in males than in females, for example, opioids are far less effective at inducing pain relief using this pain control system in females than in males. ${ }^{12-14}$

The documentation of this pain control system is largely of the male system, and we do not know what the female system looks like because, for the most part, we simply have not been looking for it. In addition, Mogil describes extensive literature on sex differences in the neuroimmune mediation of pain. It is becoming increasingly clear that the immune system is involved critically in pain processing; the work by Mogil and collaborators shows that different components of the immune system are more involved with the pain of females (e.g., significant $\mathrm{T}$ cell involvement) than males (e.g., significant glial cell involvement). ${ }^{15}$ Last, Mogil covers sex differences between cognitive, environmental, and social factors of pain in males and females.

Clearly, many significant qualitative and quantitative differences in the biology of pain exist between males and females, and given the escalating number of recent articles highlighting these differences, we may be just at the beginning stages of this research.

\section{Pregnancy As a "Stress Test"}

Pregnancy has been described as a stress test for life, ${ }^{16}$ and one must look no further than the maternal morbidity and mortality crisis in the United States to confirm that pregnancy is indeed a stress test. In the United States, we are failing that test. Unlike the rest of the world, from 2000 to 2017, the United States saw a dramatic rise in pregnancy-related deaths, which increased to 19 deaths per 100,000 births in $2017 .{ }^{17}$ An estimated 700 women die each year in the United States from conditions related to or associated with pregnancy or childbirth.
Black women die at a rate nearly four times that of white women, and Alaska Native/American Indian women die at nearly three times the rate of white women. ${ }^{18}$ In addition, $\sim 50,000$ women experience severe maternal morbidity (SMM). ${ }^{19}$

A multitude of substantial physiological, anatomical, and behavioral changes occur during pregnancy. ${ }^{20-22}$ During pregnancy, the mother's body must work harder to meet the demands of the developing fetus. Each maternal organ adapts in a variety of ways over time. ${ }^{23}$ Furthermore, the immune system needs to adapt to the presence of the allogeneic fetus to prevent rejection of the fetus. ${ }^{24}$ Pregnancy and the postpartum period encompass a time of significant biological and psychological change and stress.

\section{Pain and Pregnancy}

Pregnant women are propelled into a state that is vastly different from that of nonpregnant women. The immune and nervous systems are very involved with pain regulation and mitigation and changes significantly in pregnancy. ${ }^{25-28}$ Pregnancy causes an increase in oxytocin release, which has been implicated in pain processing. ${ }^{29}$ Jung et al. ${ }^{30}$ found a progressive rise in total plasma cortisol, corticosteroid-binding globulin, and 24-hour urinary-free cortisol during pregnancy, peaking during the third trimester, which implicates an upregulation of the maternal hypothalamic/pituitary/adrenal axis that is involved in pain processing. Physical and mechanical changes associated with pregnancy also are associated significantly with pain, for example, carrying the excess weight of pregnancy is associated with lower back pain or pelvic girdle pain ${ }^{31,32}$ and with increased knee and foot pain. ${ }^{33,34}$

Many disease states associated with maternal morbidity and mortality are painful or have the potential to exasperate existing pain states. Hemorrhage, cardiovascular and coronary conditions, infection, cardiomyopathy, embolism, preeclampsia and eclampsia, and mental health conditions are the leading causes of death associated with pregnancy in the United States. ${ }^{35}$

Pain commonly is associated with these conditions before death and is a prominent symptom of women with maternal morbidity. Although a consensus has not been developed on the exact definition of SMM, ${ }^{36}$ the Centers for Disease Control and Prevention has provided a list of 21 indicators it uses to search for instances of SMM among existing electronic health records on hospital visits. ${ }^{37}$ These indicators include acute myocardial infarction, acute renal failure, adult respiratory distress syndrome, eclampsia, cardiac arrest or ventricular fibrillation, puerperal cerebrovascular disorders, pulmonary edema or acute heart failure, sepsis, sickle cell disease with crisis, and hysterectomy. All of these indicators can have pain associated with them, and in some cases, such as sickle cell disease, the pain can be debilitating. ${ }^{38}$

However, the news is not all bad. Preclinical and clinical research has demonstrated the existence of pregnancyassociated analgesia, where being pregnant can reduce one's sensitivity to pain. In animal studies dating back to 1980 , studies in rats have shown increases in acute pain tolerance during pregnancy, and such pain tolerance increases across the pregnancy and is opioid receptor mediated. ${ }^{39}$

More recently, others have found that pregnancy could reduce the pain hypersensitivity produced in the chronic constriction injury model, in which the sciatic nerve is constricted partially with ligature, ${ }^{40}$ during late pregnancy in 
rats. ${ }^{41}$ Of note, $\mathrm{T}$ cells have been found to be involved critically in pain processing in female but not in male mice, whereas glial cells are critical to pain transmission in male but not in female mice. ${ }^{15}$ During pregnancy, the dampening of the immune system to protect the fetus ${ }^{42}$ may explain some pregnancy-induced analgesia. Rosen et al. ${ }^{43}$ have found that $\mathrm{T}$ cell-deficient pregnant mice do not exhibit pregnancyinduced analgesia, suggesting that $\mathrm{T}$ cells are involved in the mediation of pregnancy-induced analgesia.

In humans, researchers also have looked at pain thresholds in response to experimenter-induced acute pain in pregnant and postpartum women. Cogan and Spinnato ${ }^{44}$ examined the pain thresholds of women in the last few weeks of pregnancy and found that their pain thresholds to pressure stimuli increased (i.e., they experienced less pain sensitivity) as childbirth approached. Pain thresholds of nonpregnant control subjects remained unchanged. In a similar study, Ohel et al. ${ }^{45}$ found that pressure pain thresholds increased during the active phase of labor but not during prelabor, and pain responsiveness returned to normal after childbirth. Furthermore, Kammerer et al. ${ }^{46}$ found a lack of responsiveness to cold pain in women just before giving birth.

Numerous reports indicate that prepregnancy chronic pain becomes diminished during pregnancy. For example, in a prospective study by LeResche et al., ${ }^{47}$ women with musculoskeletal orofacial pain and pain-free comparison subjects completed a questionnaire assessing pain at the first, second, and third trimesters of pregnancy, as well as 1 year postpartum.

Pain decreased across the course of the pregnancy. Melhado et al. ${ }^{48}$ evaluated the presence of headache in 1,101 pregnant women with a history of headache, conducting interviews with women during the first, second, and third trimesters of pregnancy and immediately after delivery. They found that most of the headaches improved or disappeared during the second and third trimesters. Likewise, Granella et al. ${ }^{49}$ studied 1,300 women who suffered from migraine headaches without aura. Of the 943 patients who became pregnant, $17.4 \%$ had complete remission from headaches, and a significant improvement was seen in $49.9 \%$ of the pregnant patients. 49

$\mathrm{T}$ cells are implicated in the progression of rheumatoid arthritis (RA), a painful autoimmune disease, so it is not surprising that pregnancy affects RA. A review by Østensen and Villiger ${ }^{50}$ reported that about $75 \%$ of patients with RA experience improvement or even remission of arthritis during pregnancy. In terms of RA pain, Barrett et al. ${ }^{51}$ found that $66 \%$ of pregnant women with RA had decreased pain and $64 \%$ had less swelling by the third trimester. de Man et al. ${ }^{52}$ found a similar remission of RA symptoms, including the metrics of pain, but to a lesser extent than Barrett et al. ${ }^{51}$

\section{Conclusion}

Just as it has been a historical mistake to assume that by studying pain only in males one gets a picture of pain in females as well, it would be a mistake to assume that studying pain in nonpregnant females provides an understanding of pain in pregnant females. A woman's body changes dramatically with pregnancy, and many of these changes help to drive the maternal morbidity and mortality crisis in the United States.
To address the maternal mortality and morbidity crisis comprehensively, much must be done, including improving the treatment of pain during pregnancy. Although in some ways nature may be protecting pregnant women from pain, it is still a significant part of pregnancy. Like nature, we must help protect pregnant women from unnecessary suffering. To do this, we must study pain both during and after pregnancy, rather than exclude pregnant women from pain research altogether, as is too often the case. In pain research and beyond, when appropriate, it is time to consider pregnancy as a key biological variable in biomedical research.

\section{Authors' Contributions}

D.A.T., H.E.B., and J.M.W. contributed to the conceptualization of the review topic, the literature review, and writing this article.

\section{Author Disclosure Statement}

No competing financial interests exist.

\section{Funding Information}

No external funding was received to support this work.

\section{References}

1. Prendergast BJ, Onishi KG, Zucker I. Female mice liberated for inclusion in neuroscience and biomedical research. Neurosci Biobehav Rev 2014;40:1-5.

2. Woitowich NC, Beery A, Woodruff T. A 10-year follow-up study of sex inclusion in the biological sciences. Elife 2020;9:e56344.

3. Electronic Code of Federal Regulations. Drug products withdrawn or removed from the market for reasons of safety or effectiveness, 2020. Available at: https://www.hhs .gov/ohrp/regulations-and-policy/regulations/common-rule/ index.html Accessed June 18, 2020.

4. IOM Committee on Advancing Pain Research, Care, and Education Board on Health Sciences Policy. Institute of Medicine: Relieving Pain in America-A Blueprint for Transforming Prevention, Care, Education, and Research. Washington, DC: Institute of Medicine of the National Academies, 2011.

5. Ruau D, Liu LY, Clark JD, Angst MS, Butte AJ. Sex differences in reported pain across 11,000 patients captured in electronic medical records. J Pain 2012;13:228-234.

6. Mogil JS. Sex differences in pain and pain inhibition: Multiple explanations of a controversial phenomenon. Nat Rev Neurosci 2012;13:859-866.

7. Mogil JS, Chanda ML. The case for the inclusion of female subjects in basic science studies of pain. Pain 2005;117:1-5.

8. Mogil JS. Qualitative sex differences in pain processing: Emerging evidence of a biased literature. Nat Rev Neurosci 2020;21:353-365.

9. Smith SB, Parisien M, Bair E, et al. Genome-wide association reveals contribution of MRAS to painful temporomandibular disorder in males. Pain 2019;160:579-591.

10. Basbaum AI, Fields HL. Endogenous pain control mechanisms: Review and hypothesis. Ann Neurol 1978;4:451462.

11. Fields HL, Basbaum AI. Brainstem control of spinal paintransmission neurons. Ann Rev Physiol 1978;40:217-248. 
12. Doyle HH, Eidson LN, Sinkiewicz DM, Murphy AZ. Sex differences in microglia activity within the periaqueductal gray of the rat: A potential mechanism driving the dimorphic effects of morphine. J Neurosci 2017;37:3202-3214.

13. Loyd DR, Wang X, Murphy AZ. Sex differences in $\mu$-opioid receptor expression in the rat midbrain periaqueductal gray are essential for eliciting sex differences in morphine analgesia. J Neurosci 2008;28:14007-14017.

14. Averitt DL, Eidson LN, Doyle HH, Murphy AZ. Neuronal and glial factors contributing to sex differences in opioid modulation of pain. Neuropsychopharmacology 2019;44: $155-165$.

15. Sorge RE, Mapplebeck JCS, Rosen S, et al. Different immune cells mediate mechanical pain hypersensitivity in male and female mice. Nat Neurosci 2015;18:1081-1083.

16. Williams D. Pregnancy: A stress test for life. Curr Opin Obstet Gynecol 2003;15:465-471.

17. Trends in Maternal Mortality, 2000 to 2017. Estimates by WHO, UNICEF, UNFPA, World Bank Group and the United Nations Population Division. Available at: https:// www.unfpa.org/sites/default/files/pub-pdf/Maternal_mortality_ report.pdf Accessed June 18, 2020.

18. Petersen EE, Davis NL, Goodman D, et al. Racial/ethnic disparities in pregnancy-related deaths-United States, 2007-2016. MMWR Morb Mortal Wkly Rep 2019;68:762765.

19. U.S. Government Accountability Office. Maternal mortality: Trends in pregnancy-related deaths and federal efforts to reduce them, 2020. Available at: https://www.gao.gov/ assets/710/705331.pdf Accessed June 18, 2020.

20. Bhatia P, Chhabra S. Physiological and anatomical changes of pregnancy: Implications for anaesthesia. Indian J Anaesth 2018;62:651-657.

21. Soma-Pillay P, Nelson-Piercy C, Tolppanen H, Mebazaa A. Physiological changes in pregnancy. Cardiovasc J Afr 2016;27:89-94.

22. Moya J, Phillips, L Sanford J, et al. A review of physiological and behavioral changes during pregnancy and lactation: Potential exposure factors and data gaps. J Expo Sci Environ Epidemiol 2014;24:449-458.

23. Williams DJ. Physiology of healthy pregnancy. In: Warrell DA, Cox TM, Firth JD, eds. Oxford textbook of medicine, 4th ed. Oxford: Oxford University Press, 2003:383-385.

24. Erlebacher A. Why isn't the fetus rejected? Curr Opin Immunol 2001;13:590-593.

25. Harris L, Aplin JD. Vascular remodeling and extracellular matrix breakdown in the uterine spiral arteries during pregnancy. Reprod Sci 2007;14:28-34.

26. Smith SD, Dunk CE, Aplin JD, et al. Evidence for immune cell involvement in decidual spiral arteriole remodeling in early human pregnancy. Am J Pathol 2009;174: 1959-1971.

27. Mor G, Cardenas I. The immune system in pregnancy: A unique complexity. Am J Reprod Immunol 2010;63: 425-433.

28. PrabhuDas M, Bonney E, Caron K, et al. Immune mechanisms at the maternal-fetal interface: Perspectives and challenges. Nat Immunol 2015;16:328-334.

29. Goodin BR, Ness TJ, Robbins MT. Oxytocin-A multifunctional analgesic for chronic deep tissue pain. Curr Pharm Des 2015;21:906-913.

30. Jung C, Ho JT, Torpy DJ, et al. A longitudinal study of plasma and urinary cortisol in pregnancy and postpartum. J Clin Endocrinol Metab 2011;96:1533-1540.
31. Casagrande D, Gugala Z, Clark SM, Lindsey RW. Low back pain and pelvic girdle pain in pregnancy. J Am Acad Orthop Surg 2015;23:539-549.

32. Ogollah R, Bishop A, Lewis M, Grotle M, Foster NE. Responsiveness and minimal important change for pain and disability outcome measures in pregnancy-related low back and pelvic girdle pain. Phys Ther 2019;99:1551-1561.

33. Varol T, Göker A, Cezayirli E, Özgür S, Tuç Yücel A. Relation between foot pain and plantar pressure in pregnancy. Turk J Med Sci 2017;47:1104-1108.

34. Vullo VJ, Richardson JK, Hurvitz EA. Hip, knee, and foot pain during pregnancy and the postpartum period. J Fam Pract 1996;43:63-68.

35. Centers for Disease Control and Prevention. Report From Nine Maternal Mortality Review Committees. Available at: https://reviewtoaction.org/sites/default/files/national-portalmaterial/Report\%20from\%20Nine\%20MMRCs\%20final_0 .pdf Accessed June 18, 2020.

36. Creanga AA, Berg CJ, Ko JY, et al. Maternal mortality and morbidity in the United States: Where are we now? J Womens Health (Larchmt) 2014;23:3-9.

37. Centers for Disease Control and Prevention. How does CDC identify severe maternal morbidity? Available at: https://www.cdc.gov/reproductivehealth/maternalinfant health/smm/severe-morbidity-ICD.htm Accessed June 18, 2020.

38. Benjamin L. Pain management in sickle cell disease: Palliative care begins at birth? Hematology Am Soc Hematol Educ Program 2008;2008:466-474:DOI: 10.1182/asheducation2008.1.466.

39. Gintzler AR. Endorphin-mediated increases in pain threshold during pregnancy. Science 1980;210:193-195.

40. Bennett GJ, Xie YK. A peripheral mononeuropathy in rat that produces disorders of pain sensation like those seen in man. Pain 1988;33:87-107.

41. Onodera Y, Kanao-Kanda M, Kanda H, Sasakawa T, Iwasaki H, Kunisawa T. Pregnancy suppresses neuropathic pain induced by chronic constriction injury in rats through the inhibition of TNF- $\alpha$. J Pain Res 2017;10:567-574.

42. Saito S, Nakashima A, Shima T, Ito M. Th1/Th2/Th17 and regulatory $\mathrm{T}$ cell paradigm in pregnancy. Am $\mathrm{J}$ Reprod Immunol 2010;63:601-610.

43. Rosen SF, Ham B, Drouin S, et al. T cell mediation of pregnancy analgesia affecting chronic pain in mice. J Neurosci 2017;37:9819-9827.

44. Cogan R, Spinnato JA. Pain and discomfort thresholds in late pregnancy. Pain 1986;27:63-68.

45. Ohel I, Walfisch A, Shitenberg D, et al. A rise in pain threshold during labor: A prospective clinical trial. Pain 2007;132:S104-S108.

46. Kammerer M, Adams D, von Castelberg B, Glover V. Pregnant women become insensitive to cold stress. BMC Pregnancy Childbirth 2002;2:8.

47. LeResche L, Sherman JJ, Huggins K, et al. Musculoskeletal orofacial pain and other signs and symptoms of temporomandibular disorders during pregnancy: A prospective study. J Orofac Pain 2005;19:193-201.

48. Melhado EM, Maciel JA Jr, Guerreiro CAM. Headache during gestation: Evaluation of 1101 women. Can J Neurol Sci 2007;34:187-192.

49. Granella F, Sances G, Zanferrari C, Costa A, Martignoni E, Manzoni GC. Migraine without aura and reproductive life events: A clinical epidemiology study in 1300 women. Headaches 1993;33:385-389. 
50. Østensen M, Villiger PM. The remission of rheumatoid arthritis during pregnancy. Semin Immunopathol 2007;29: 185-191.

51. Barrett JH, Brennan P, Fiddler M, Silman AJ. Does rheumatoid arthritis remit during pregnancy and relapse postpartum? Results from a nationwide study in the United Kingdom performed prospectively from late pregnancy. Arthritis Rheum 1999;42:1219-1227.

52. de Man YA, Dolhain RJEM, van de Geijn FE, Willemsen SP, Hazes JMW. Disease activity of rheumatoid arthritis during pregnancy: Results from a nationwide prospective study. Arthritis Rheum 2008;59:1241-1248.
Address correspondence to: David A. Thomas, PhD Office of Research on Women's Health Office of the Director National Institutes of Health 6707 Democracy Boulevard (Democracy II), Suite 400 Bethesda, MD 20892-5484

E-mail: david.thomas@nih.gov 